\title{
Critical distance between two irregular adjacent buildings in order to prevent collision during earthquake
}

DOI : 10.36909/jer.13929

\author{
Yaghub Ebrahimi, Ali Hemmati*, Ali Reza Mortezaei, Mahmud Nikkhah \\ Shahmirzadi \\ Civil Engineering Department, Islamic Azad University, Semnan Branch, Semnan, Iran. \\ *Email: ali.hemmati@semnaniau.ac.ir; Corresponding Author.
}

ABSTRACT
The aim of this study is to evaluate the value of suitable distance due to prevent the impact
between two irregular adjacent buildings when earthquake is caused to occur large lateral displacement and damage the elements of buildings. For this purpose, by using a mathematical program based on neural network, the number of stories, the period and height of investigated models, PGD, PGV and PGA of earthquake records are defined and the nonlinear lateral displacements of different structures are determined in order to use in the program. Thus, the results of displacements based on all inputs are listed and the minimum critical distance is approximately estimated based on especial regression. For instance, a 3-4 story model is numerically investigated by Tabas earthquake record, which is suggested to provide required gap size about $70 \mathrm{~cm}$. In fact, each model has to observe a $35 \mathrm{~cm}$ gap. A newly developed program based on mathematical equations are applied for determining the lateral displacements of each story. A new mathematical formula is proposed by neural network, which shows the least distance between irregular adjacent buildings. For investigating the accuracy of formula, two different ways are performed and the results of analyses confirm suggested equation. For this challenge, a 2-4 story model is considered and three different critical distances are calculated to be 59,62 and $75 \mathrm{~cm}$ which show the last gap size is able to provide safety gap size, determined by suggested formula.

Key words: building period; collision; irregular building; neural network; pounding. 


\section{INTRODUCTION}

Insufficient gap size between tall buildings is usually caused to collide when lateral displacements exceed the normal limitations and adjacent structures experience impact from each other. A value of separation distance is generally considered to cover relative displacement for avoiding collision between adjacent structures during seismic excitations but due to the cost of land in metropolitan areas, owners do not often like to provide critical distance, which designers has suggested and consequently, pounding hazard is increased even for tall building against two or three story buildings. For instance, a three story building was caused to damage the tower of AW hotel by the Alaskan earthquake of 1964 (Pantelides 1998). Many other reports in field of earthquake have presented the pounding between adjacent structures due to insufficient gap size by San Fernando, Mexico City, Loma Prieta and Chi Chi earthquake (Jankowski 2009, Aguilar et al. 1989, Kasai and Maison 1997, Lin and Weng 2002). In order to calculate safety space between two buildings, a typical equation based on relative displacements of each building is used, which is expressed by (Kasai and Maison 1997):

$$
S=\sqrt{\delta_{i}^{2}+\delta_{j}^{2}-2 \cdot \rho \cdot \delta_{i} \cdot \delta_{j}}
$$

Where, where $\delta_{i}$ and $\delta_{j}$ are maximum lateral displacement of buildings $\mathrm{i}$ and $\mathrm{j}$, respectively. It is also mentioned that $\rho$ is a reduction factor, which is recommended to be $0 \leq \rho \leq 1$. The value of $\rho$ can be automatically declined to zero by shifting the damping coefficient to zero, which is caused to increase lateral displacement. Kasai et al. (1996) have represented an equation based on the period and damping ratio of buildings, which decreases the separation distance by increasing damping constant or the ratio of periods. Numerical simulations on the pounding responses between a symmetric rectangular-shaped building and an asymmetric L-shaped building were carried out by Bi et al. (2017) and some relations presented. Kheyroddin et al. (2018) studied the effect of lateral structural systems of adjacent 
buildings on pounding force. Moment resisting frame, X-bracing, shear wall and dual systems were investigated and the results presented. Naderpour et al. (2017) have evaluated the value of $\rho$ using neural network and suggested an equation to determine $\rho$ based on period of structures. On the other hand, different earthquake codes have recommended a value of gap size equal to sum of their individual lateral displacement, calculated by elastic analyses or more than $\mathrm{R} \%$ of the structure height. In other researches, Der Kiureghian (1981), Garcia (2004), Penzien (1997), Varnote (2008), Hao and Shen (2001), Valles and Rainhorm (1997) and finally, Fillinfart and Cervantes (1995) have focused significantly on critical distance by numerical and experimental analyses between structures based on different parameters such as period of buildings, damping ratio and other effective properties of buildings. Considering period of structures as one of the most important parameters, nonlinear value of period is defined to calculate the value of $\rho$ by Jeng and Tzeng (2000) and Khatami et al. (2019). For this purpose, second value of period is parametrically described by different equations and separation distance between structures is suggested. Therefore, separation distance can be expressed by considering different situation and various parameters for regular buildings. Hence, in this study, a value of critical distance is suggested using properties of structure and earthquake record focusing on irregular buildings. For this challenge, the number of story $(\mathrm{N})$, the period $(\mathrm{T})$ and the height $(\mathrm{H})$ of each building, peak ground acceleration (PGA), peak ground velocity (PGV) and peak ground displacement (PGD) are basically considered and by using suggested equation, critical distance is mathematically measured to avoid collision between structures and also save the land.

\section{MATERIALS AND METHODS}

In this study, in order to investigate the effect of separation distance and suggest a new equation to calculate critical distance between two irregular adjacent buildings, an original model with one, two, three, four and five story are considered to have a total height of 3, 6, 
9, 12 and $15 \mathrm{~m}$, respectively. The models are assumed to be reinforced concrete with $f_{c c}=25 \mathrm{~N} / \mathrm{mm}^{2}$ and $F_{y}=380 \mathrm{~N} / \mathrm{mm}^{2}$. The dimension of each direction is $20 \mathrm{~m}$ in first story, included five 4 meter spans using columns with $35^{*} 35 \mathrm{~cm}$ for story no. 1 and story no. 2 and $30 * 30 \mathrm{~cm}$ for story no 3,4 and 5 and all beams are also $25 * 30 \mathrm{~cm}$. In order to change the regular building to an irregular model, first story is assumed to be complete with 5 spans, second story has 4 spans, third story has 3 spans, fourth story has 2 spans and fifth story has one span for 5 story model (Loghmani et al. 2020).

The current study has investigated linear elastic models, as lateral displacement responses are decreased when inelastic behavior is considered (Anajafi and Medina 2019, Ghomi Gharaei et al. 2013, Anajafi et al. 2020a). It is worth to mention that the soil structure is assumed to be same and the behavior of models is not depended on soil structure interaction. The inherent damping of the building is also modeled using 5\% Rayleigh damping (Leger and Dussault 1992, Kamgar et al. 2020, Anajafi et al. 2020b, Charney 2008).

Therefore, in order to investigate the irregular system, two value of irregularity is determined based on ASCE (2005), shown in Figure 1, which are expressed by Equation (2). Where, A and L shown in Figure 1.

$$
\begin{aligned}
& \frac{A}{L}>0.25 \\
& \left(\frac{L_{i}}{L_{j}}\right)_{\max }>1.3
\end{aligned}
$$



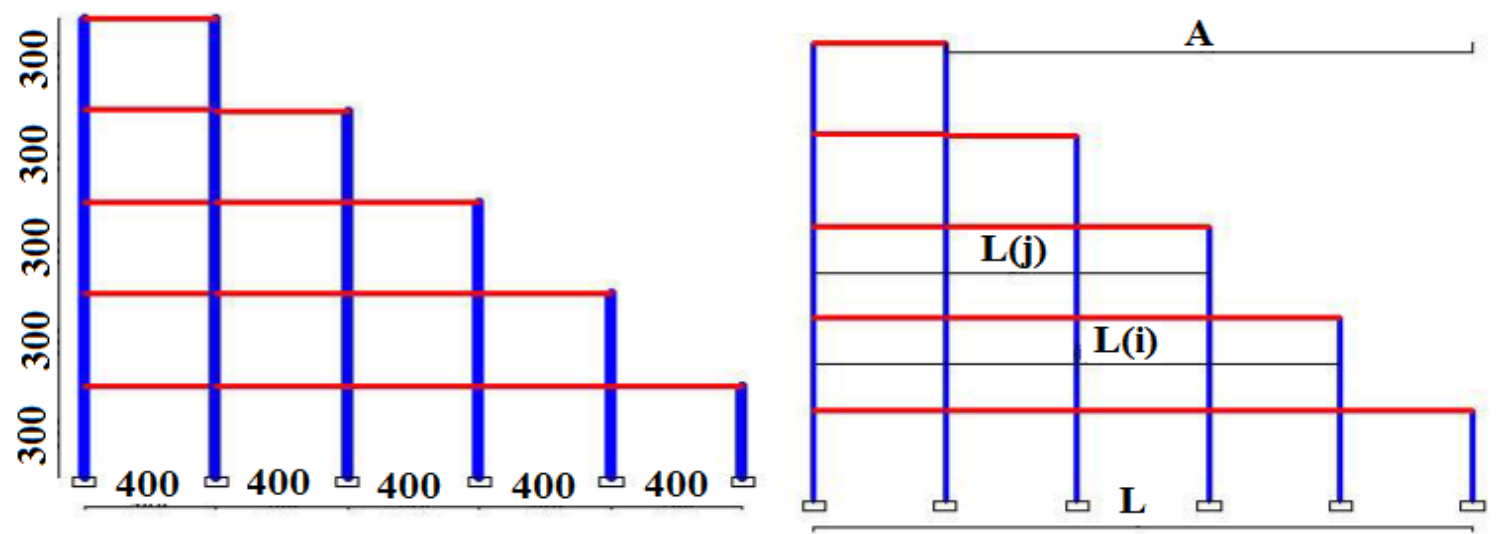

Figure 1 Elevation of assumed model

In the case of lateral loading, seven moderate ground motions are selected which are Imperial Valley (1979), Kobe (1995), Loma Prieta (1989), Landers (1992), Northridge (1994), Tabas (1978) and Duzco (1999) with the range of PGAs from $0.29 \mathrm{~g}$ to $0.95 \mathrm{~g}$. The detail of earthquake records is seen in Table 1.

Table 1 Properties of earthquake records used in the analysis.

\begin{tabular}{|c|r|r|r|r|c|}
\hline Earthquake & \multicolumn{1}{|c|}{ Date } & Magnitude & $\begin{array}{c}\text { PGA } \\
(\mathbf{c m} / \mathbf{s} 2)\end{array}$ & PGV (cm/s) & PGD (cm) \\
\hline Imperial Valley & 1979 & 6.5 & 284 & 31.49 & 13.19 \\
\hline Kobe & 1995 & 7.2 & 338 & 27.67 & 9.7 \\
\hline Loma Prieta & 1989 & 6.9 & 360 & 44.7 & 19.61 \\
\hline Landers & 1992 & 7.3 & 853 & 9.42 & 5.76 \\
\hline Northridge & 1994 & 6.7 & 557 & 41.96 & 5.71 \\
\hline Tabas & 1978 & 7.4 & 821 & 61.84 & 8.41 \\
\hline Duzco & 1999 & 7.2 & 933 & 70.27 & 9.55 \\
\hline
\end{tabular}

Following to the objective of study, sufficient separation distance between adjacent buildings can decrease pounding hazard during earthquake records. For this challenge and with respect to models and records, a newly developed program based on mathematical equations is written, which is able to model irregular buildings based on mass and stiffness matrix and also analyses based on selected records to show lateral displacements of each story during seismic excitations. In here, five different packages are informed focusing on adjacent models and earthquake records. First package is assigned to define one story building which is modeled one story to one, two, three, four and five story and analyzed with seven earthquakes records. Other packages are also described for two, three, four and five story 
model. Analyses are carried out step by step to find the nearest distance between adjacent buildings that collision is not shown during lateral loading. Two models are considered to be located close one to another, taking into account all possible combinations from the point of view of different number of stories. For instance, a 5-3 model makes a five-story building adjacent to the three-story model. The period of models, the height of buildings, the number of stories of each model and peak ground acceleration, velocity and displacement of each earthquake record are collected and listed as input and the nearest distance is assumed to be final response as output. All models are completely analyzed and the results of analyses with different earthquake records are depicted. The shortest distance between two adjacent buildings, which preventing collision during seismic excitation, is selected as optimum separation distance. The results of analyses in terms of lateral displacement considering required separation distance are shown in Figure 2.

According to the Figure 2, it seems that by increasing the number of story and also peak ground acceleration, the value of required separation distance is increased. As it is obviously seen, the maximum value of distance is suggested to be $95 \mathrm{~cm}$ for $4-5$ story model using Duzce earthquake record and the minimum critical distance is considred to be $18 \mathrm{~cm}$ for 2-3 story using Imperial Valley earthquake record. The results of analyses demonstrate Kobe and Landers earthquake records have shown the minimum and maximum required gap size among all earthquake records. For example, using Kobe earthquake record, critical distance has suggested to be $20 \mathrm{~cm}, 20 \mathrm{~cm}, 16 \mathrm{~cm}, 28 \mathrm{~cm}, 26 \mathrm{~cm}$ and $24 \mathrm{~cm}$ for $2-3$ story model, 2-4 story model, 2-5 story model, 3-4 story model, 3-5 story model and finally, 4-5 story model, respectively. 


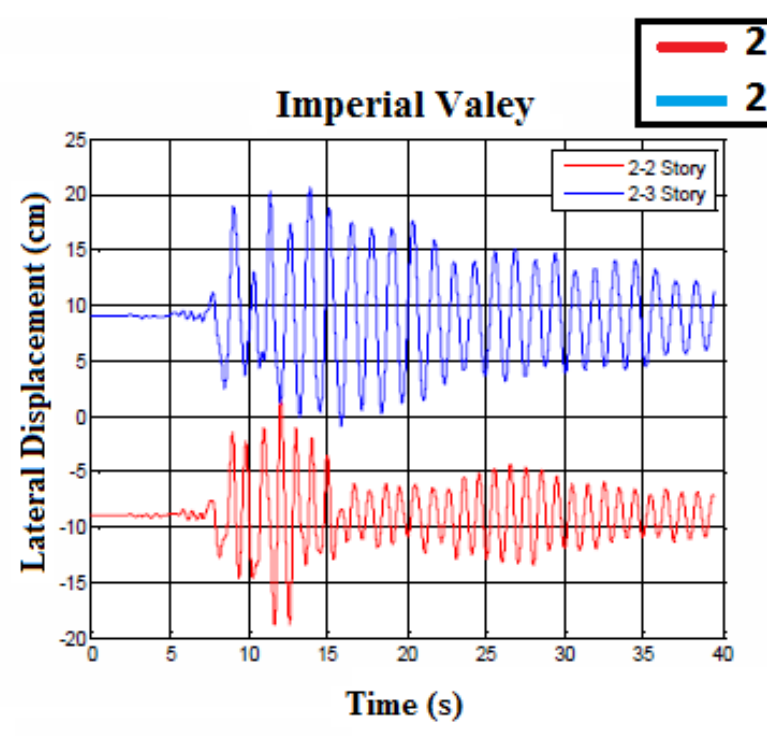

2-2 Story
2-3 Story

Kobe

$18 \mathrm{~cm}$

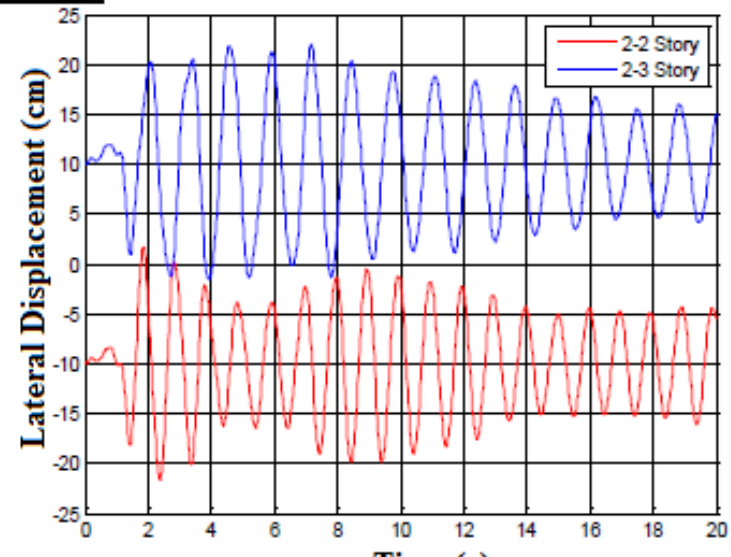

Time (s)

Loma prieta

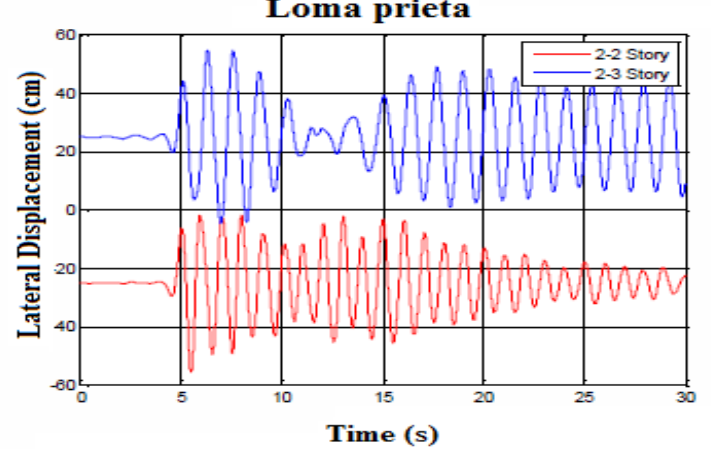

$20 \mathrm{~cm}$

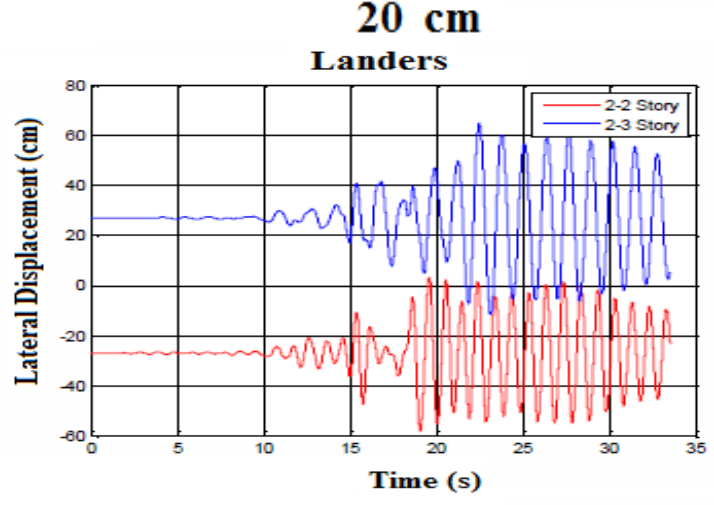

$50 \mathrm{~cm}$

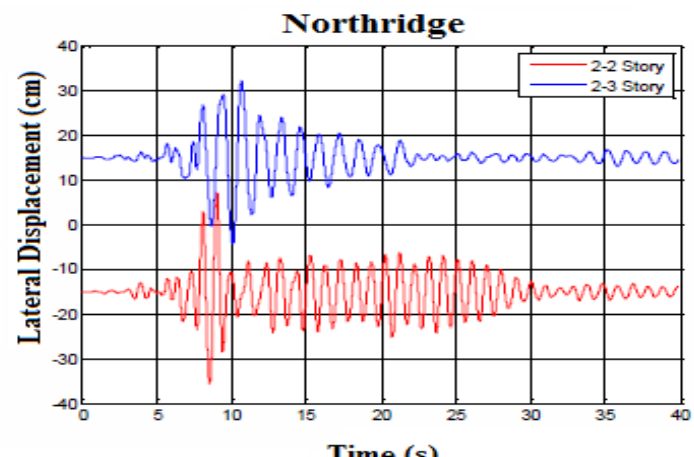

$54 \mathrm{~cm}$

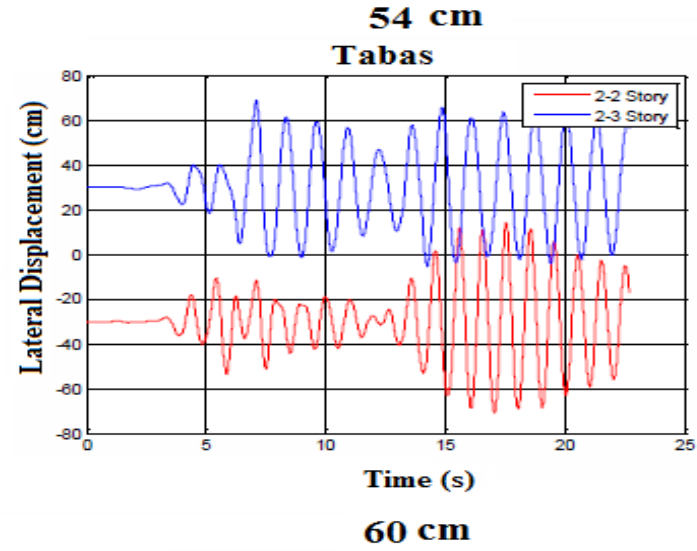

$30 \mathrm{~cm}$

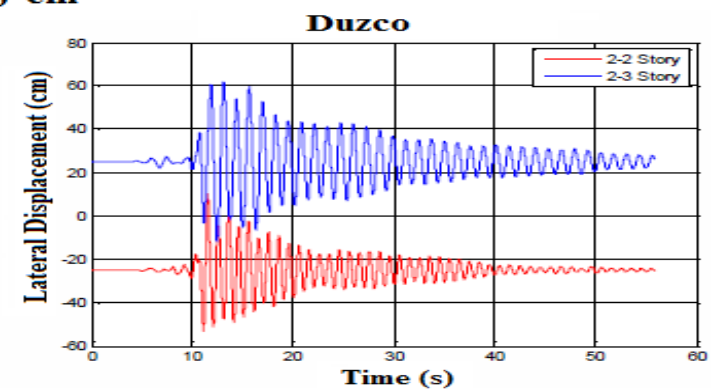

$50 \mathrm{~cm}$

a) 2-3 story 


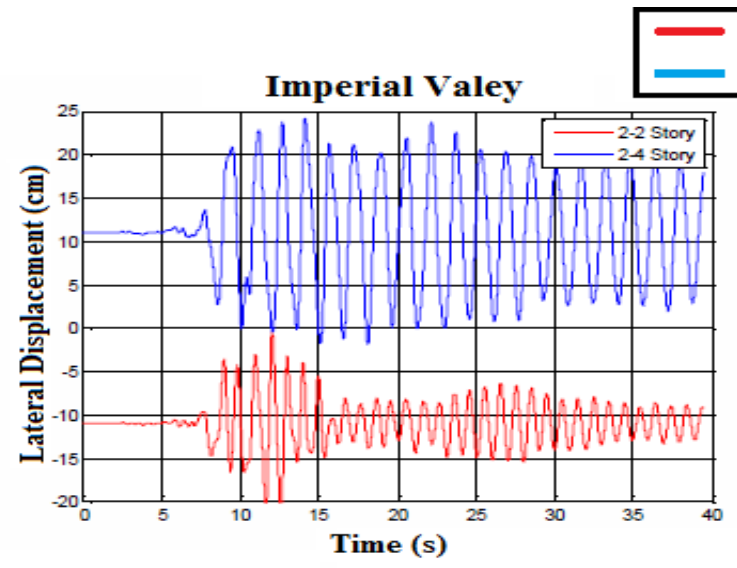

2-2 Story

2-4 Story

Kobe

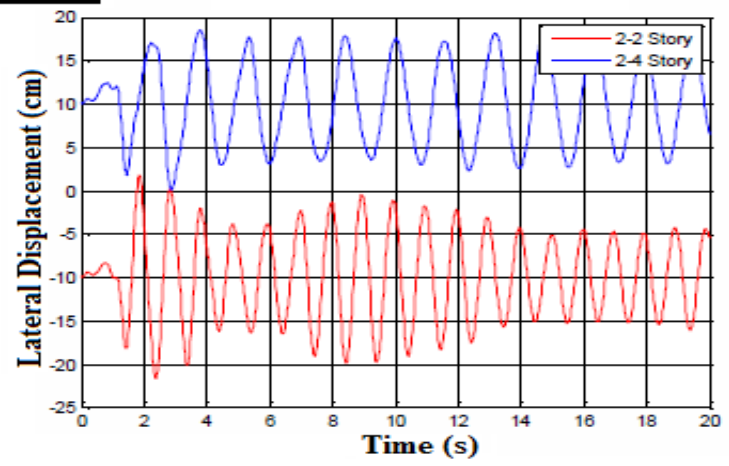

$22 \mathrm{~cm}$

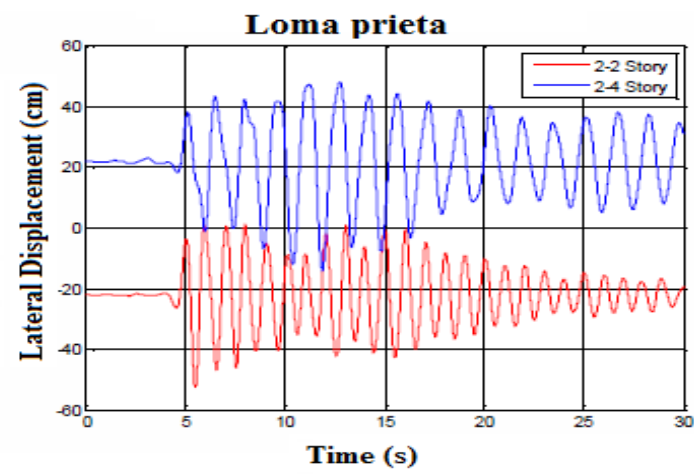

$20 \mathrm{~cm}$

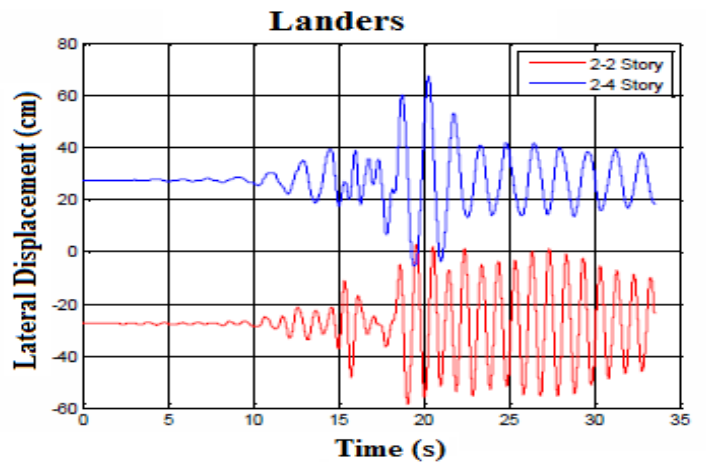

$44 \mathrm{~cm}$

Northridge

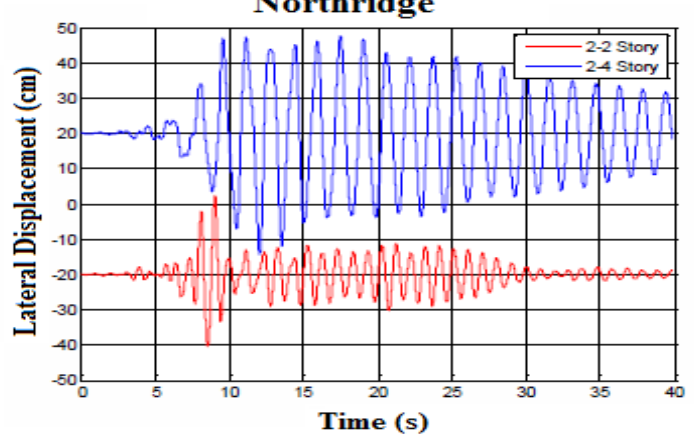

$55 \mathrm{~cm}$

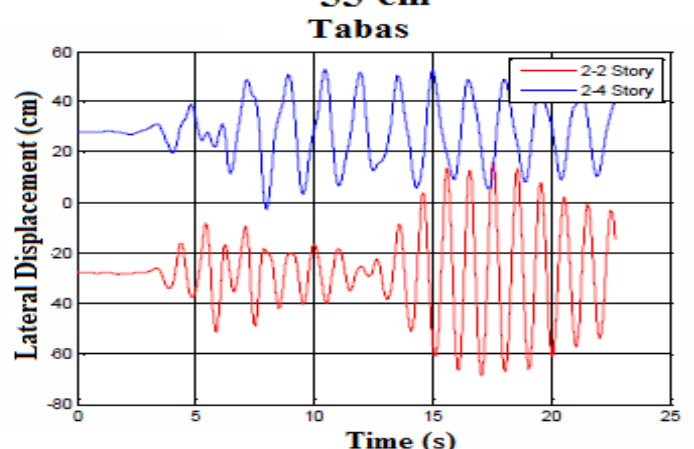

$40 \mathrm{~cm}$

$56 \mathrm{~cm}$

Duzco

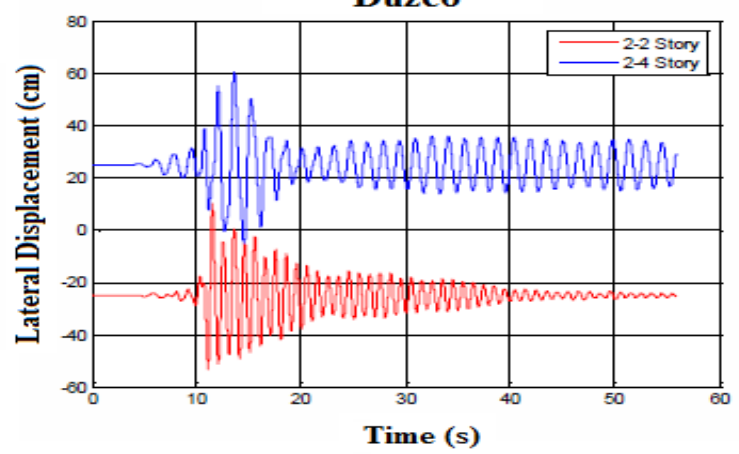

$50 \mathrm{~cm}$

b) 2-4 story 


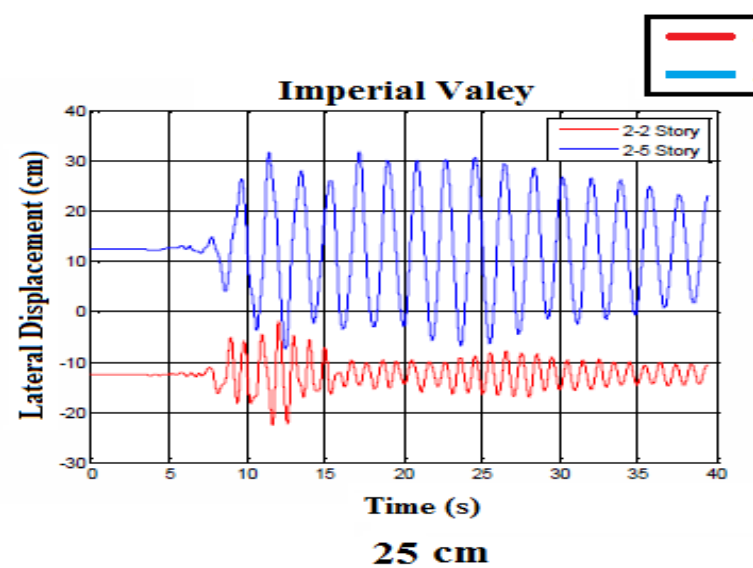

2-2 Story

2-5Story

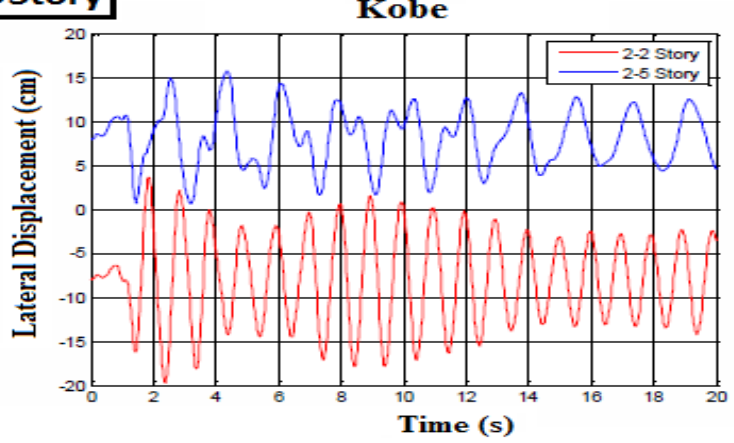

$16 \mathrm{~cm}$
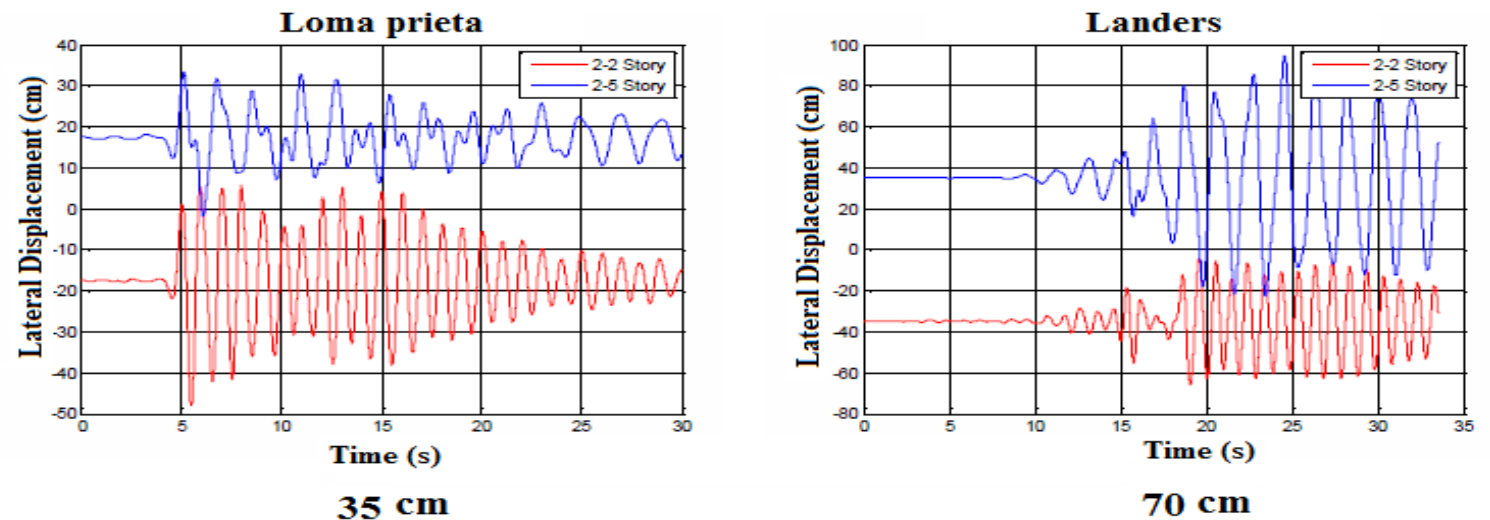

$35 \mathrm{~cm}$
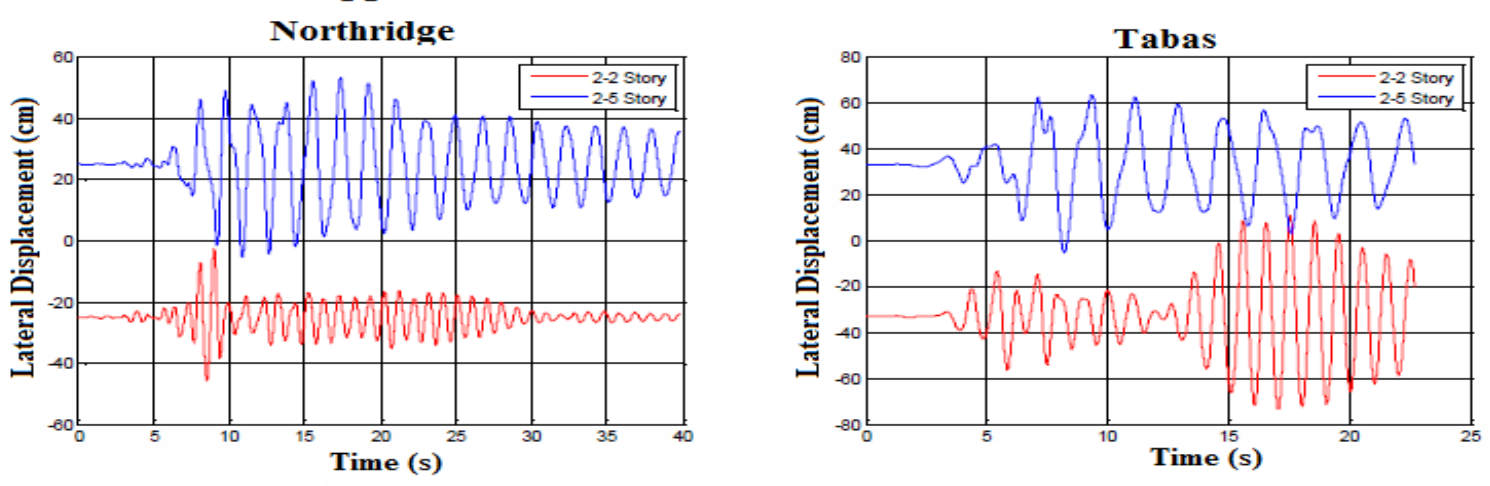

$50 \mathrm{~cm}$

$67 \mathrm{~cm}$

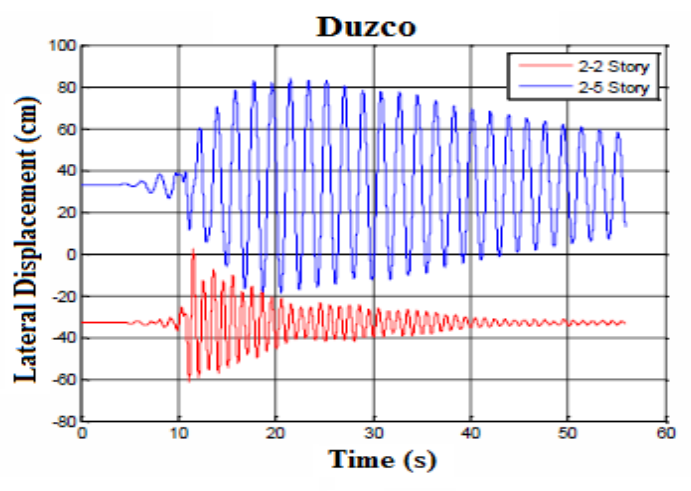

$65 \mathrm{~cm}$

c) 2-5 story 


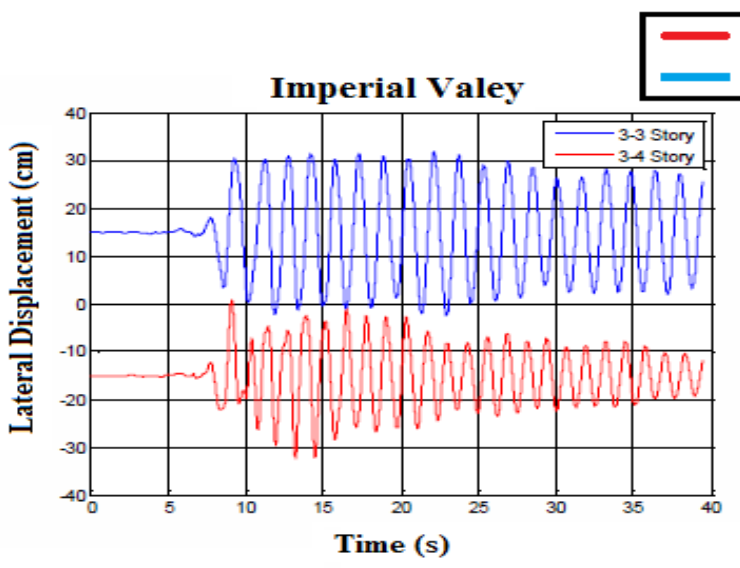

$30 \mathrm{~cm}$

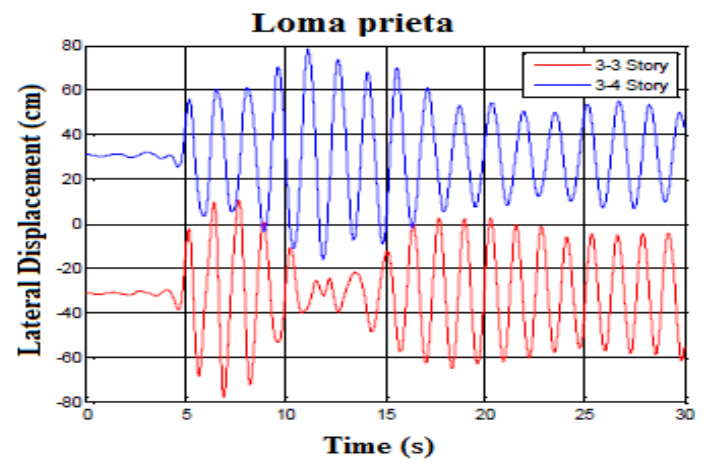

$62 \mathrm{~cm}$

Northridge

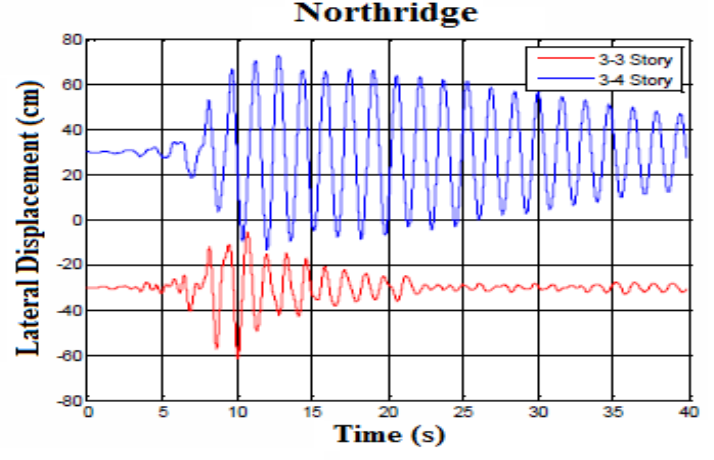

$60 \mathrm{~cm}$

\section{\begin{tabular}{ll|} 
3-3 & Story \\
3-4 & Story
\end{tabular}}

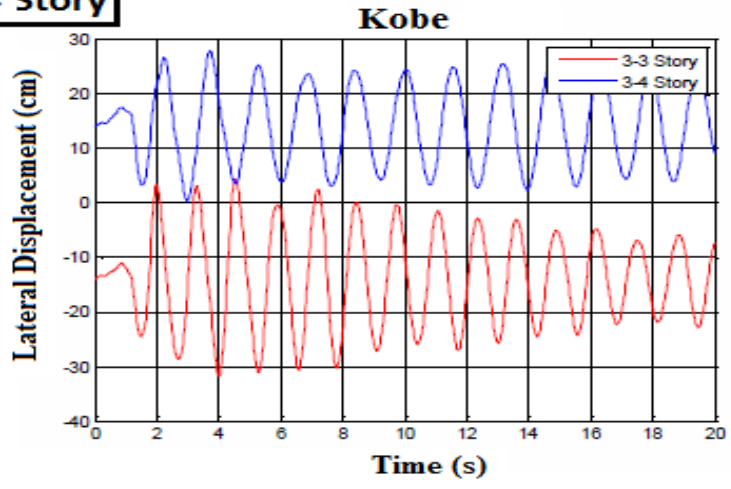

$28 \mathrm{~cm}$

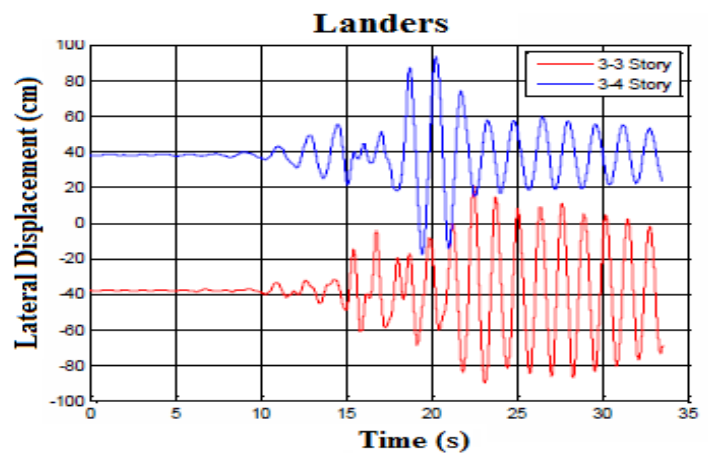

$76 \mathrm{~cm}$

Tabas

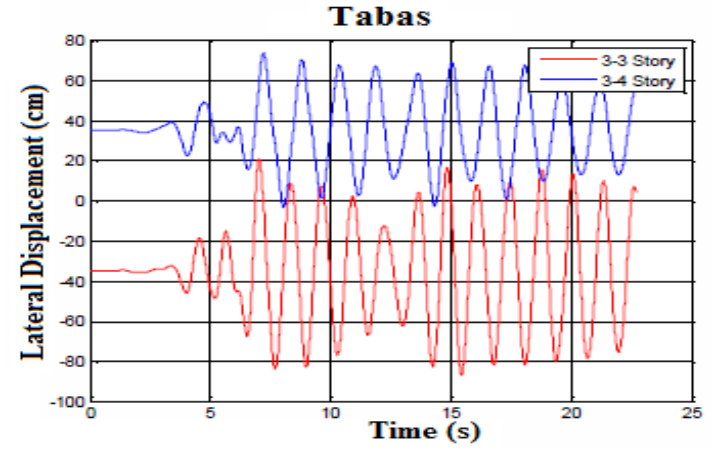

$70 \mathrm{~cm}$

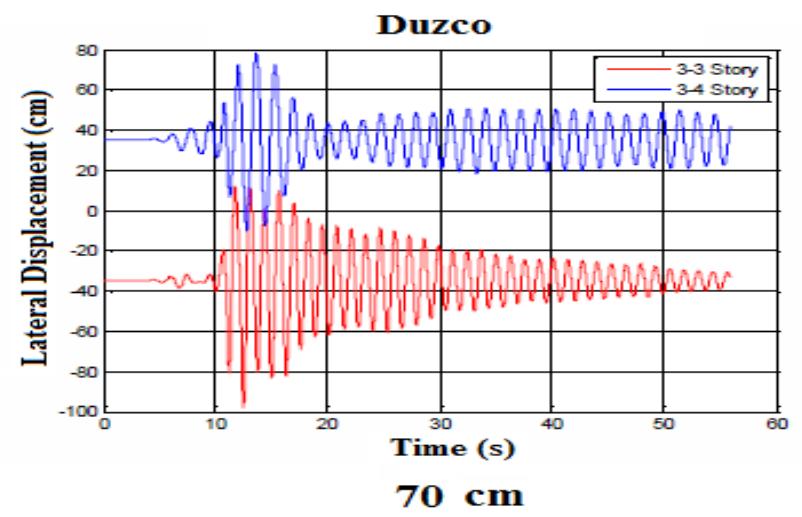

d) 3-4 story 


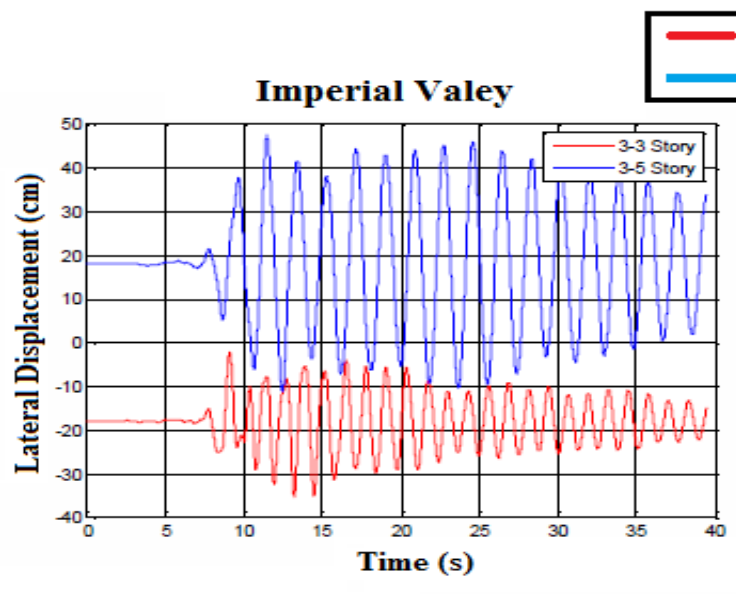

\section{3-3 Story
3-5 Story}
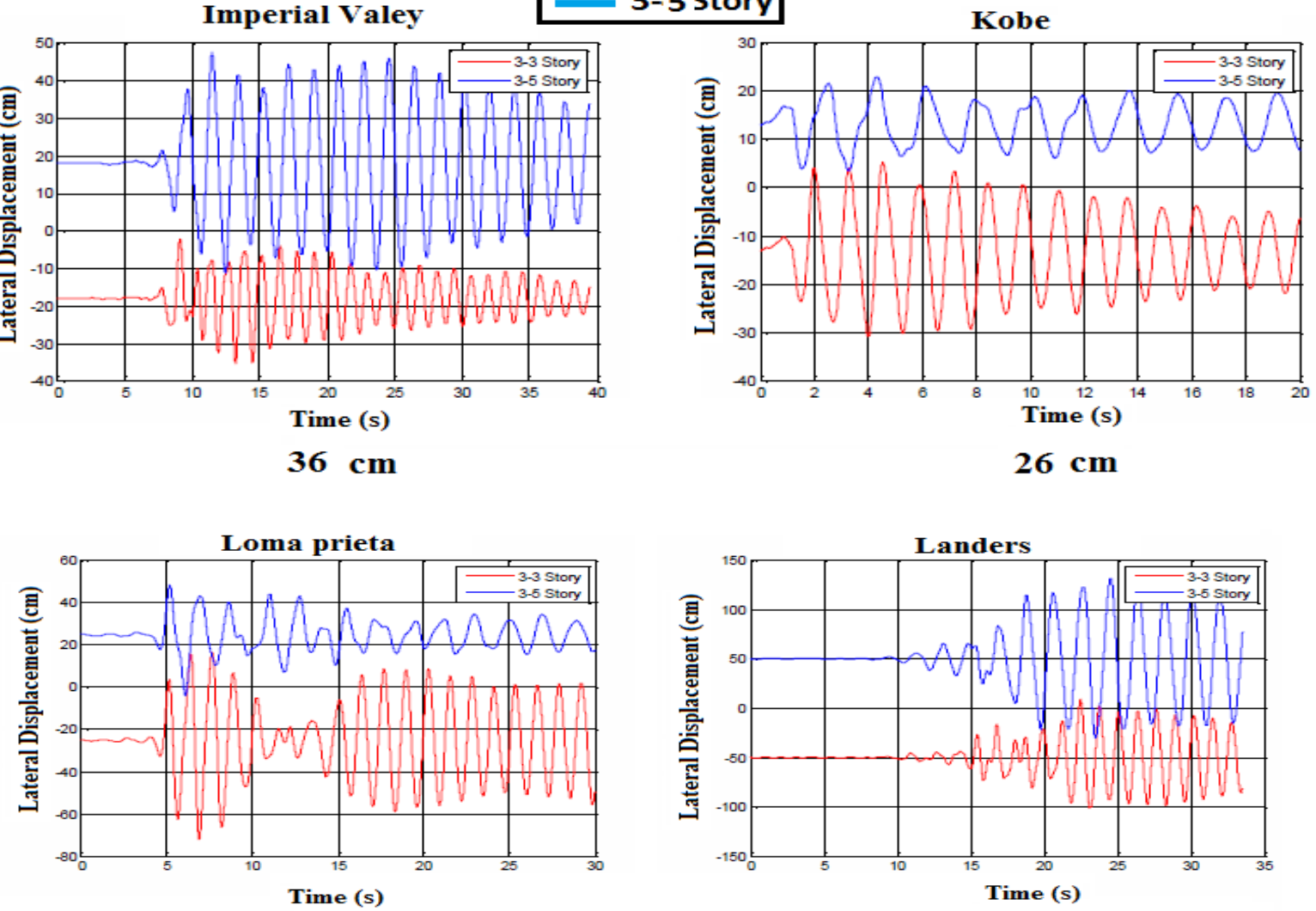

$50 \mathrm{~cm}$

$100 \mathrm{~cm}$

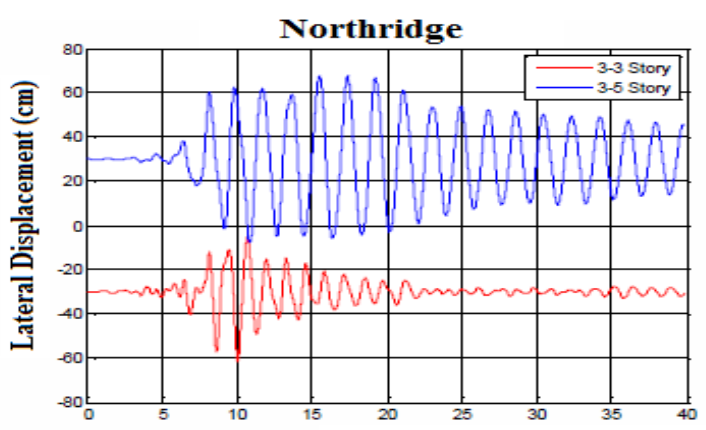

Time (s)

$60 \mathrm{~cm}$

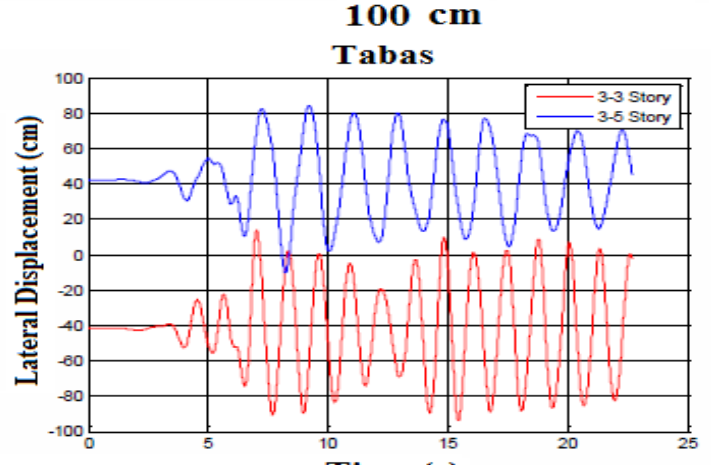

Time (s)

$84 \mathrm{~cm}$

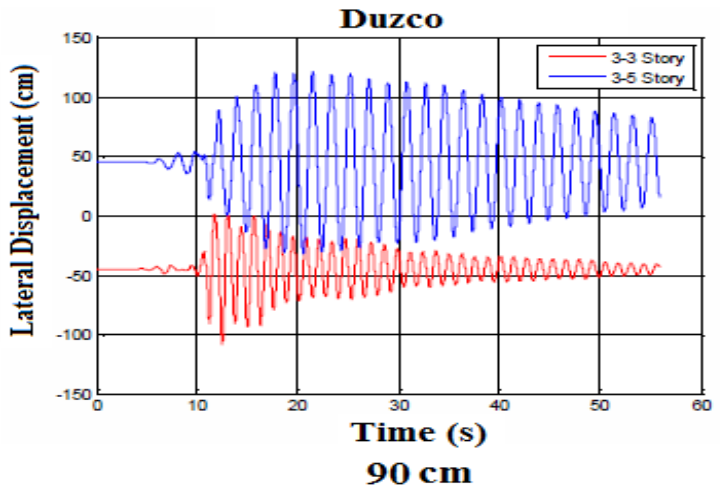

e) 3-5 story 

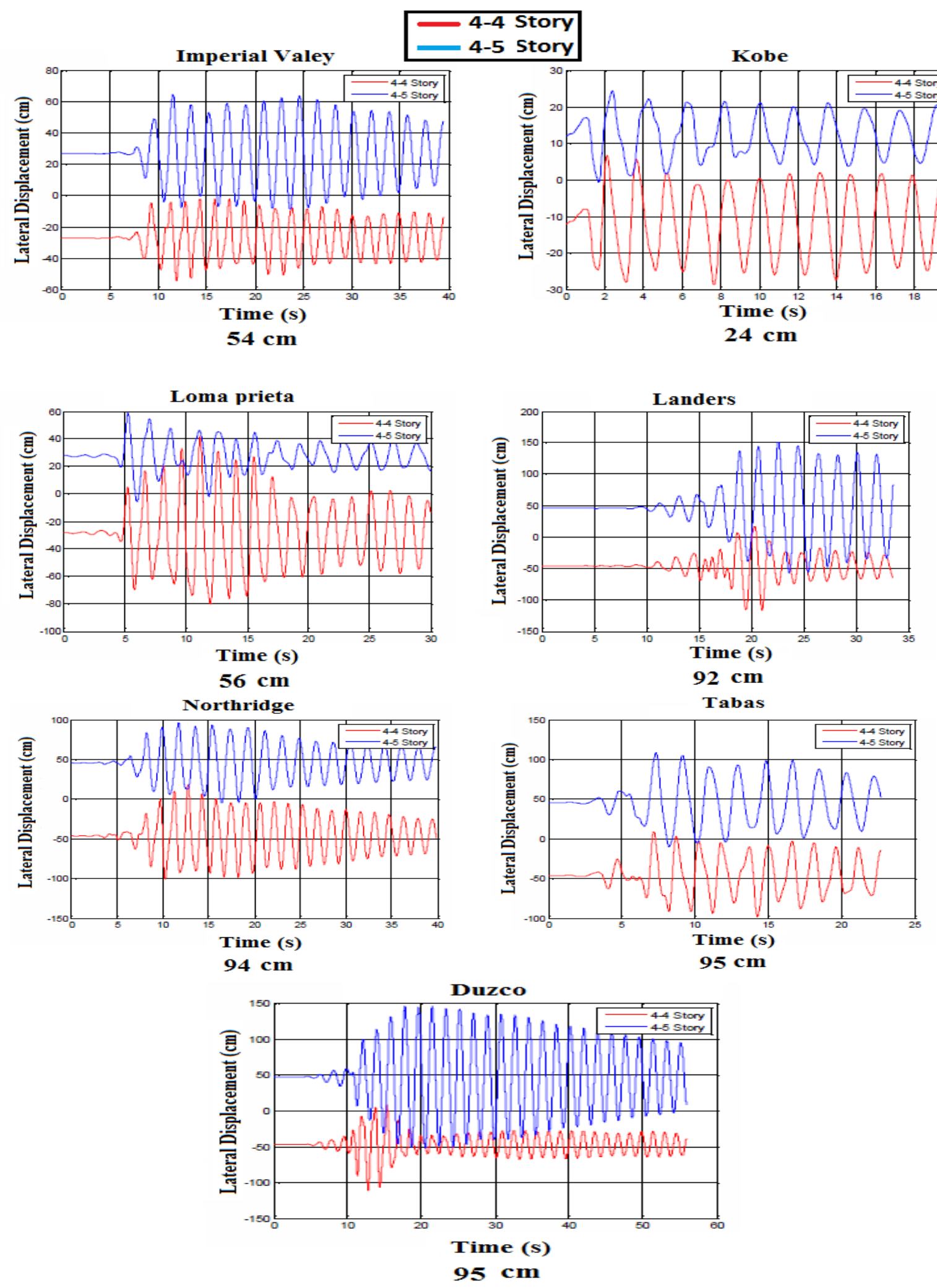

f) 4-5 story

Figure 2 Results of analyses in terms of lateral displacement considering required separation distance a) 2-3 story b) 2-4 story c) 2-5 story d) 3-4 story e) 3-5 story f)4-5 story

As it is seen in the figures, critical distance between two buildings has provided safety situation for buildings to avoid collision during earthquakes. For example, Imperial Valley 
earthquake record has shown a critical distance about $18 \mathrm{~cm}, 21.5 \mathrm{~cm}$ and $23 \mathrm{~cm}$ for 2-3, 2-4 and 2-5 model, while are $38 \mathrm{~cm}$ and $44 \mathrm{~cm}$ for 3-5 and 4-5 model, respectively. In fact, increasing the number of story has been caused to increase sufficient distance between buildings. So, there is a fluctuation trend by increasing PGA while is an increasing trend by increasing the number of story in all models. The trends of required separations distance are observed in Figure 3.

Using neural network, special trend of separation distance based on peak ground acceleration is predicted and graphically depicted for each model. For this challenge, the number of story, the height of stories, period of buildings and the information of earthquake records are listed as input and predicted separation distances are assumed as output. Thus, neural network starts to learn and find a new trend based on outputs and estimates required separation distances which can be able to cover all situations with different records. Therefore, based on the results of neural network in zone of critical distance, an increasing trend is seen by growing peak ground acceleration between buildings.
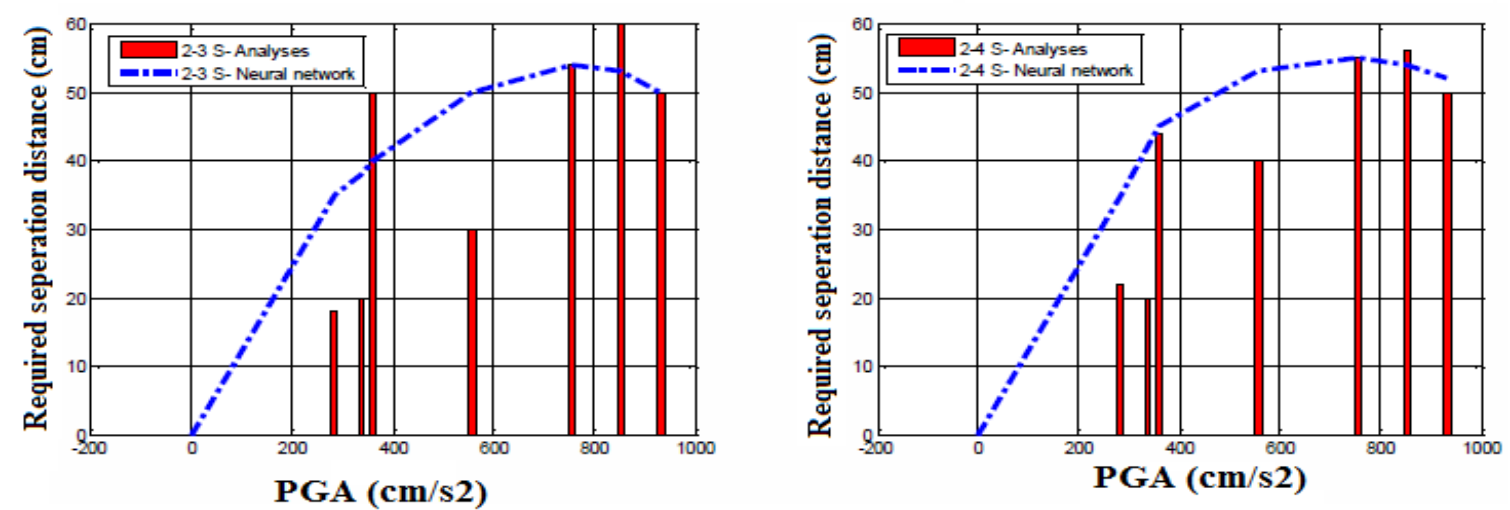

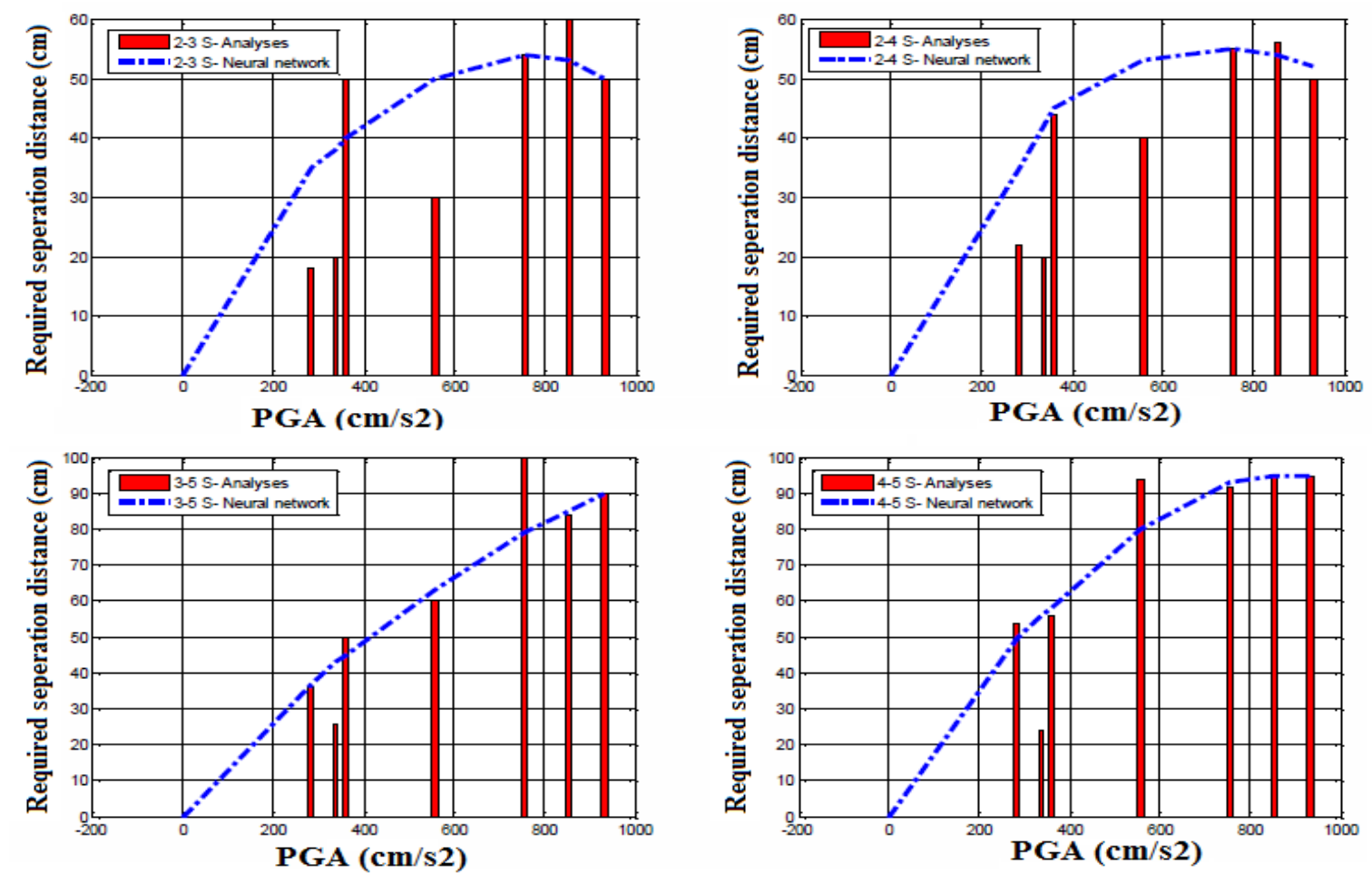

Figure 3 Required separation gap with relation to PGA of earthquake records for different structural arrangements

The results of separation distance with neural network are collected and assigned based on peak ground acceleration, which follows a linear trend to justify an equation for providing sufficient separation distance between two irregular buildings. For this purpose and having all coordinated results and also using different parameters, an iterative procedure is approximately designed which keeps dimension of equation correctly which is seen in Figure 4. First equation shows the relation between peak ground acceleration and period of models, which can not cover sufficient gap size between models and needs to an increasing factor. Hence, second equation is expressed by adding peak ground displacement and the height of shortest model, which is also needed to use a new value of increasing factor to cover sufficient gap size. Finally, an equation is numerically created to estimate safety critical distance by using all parameters and respect to dimension of equation, which is written as:

$$
S_{e s}=\left(\frac{\alpha}{N+M}\right) \frac{P G A \cdot P G D}{P G V} \cdot\left(\frac{h_{N}}{h_{M}}\right) \cdot\left(\frac{T_{N} \cdot T_{M}}{T_{N}+T_{M}}\right)
$$

Where, $S_{e s}$ denotes estimated separation distance, $\mathrm{N}$ and $\mathrm{M}$ are the number of stories $(\mathrm{N}>\mathrm{M})$ 
and PGA, PGV and PGD are informed as peak ground acceleration, velocity and displacement, respectively. In continue $\mathrm{h}$ and $\mathrm{T}$ are the height and the period of each model. In fact, $h_{N}$ and $T_{N}$ demonstrate the height of building and vibration period of building $\mathrm{N}$ and also similarly for building M. Finally, the value of $\alpha$ depends significantly on peak ground acceleration, which is recommended to be:

$\alpha=\left\{\begin{array}{c}0.85 \rightarrow \quad P G A<350 \quad \mathrm{~cm} / \mathrm{s}^{2} \\ 1.15 \rightarrow \quad 350 \leq P G A<650 \quad \mathrm{~cm} / \mathrm{s}^{2} \\ 2.65 \rightarrow \quad P G A \geq 650 \quad \mathrm{~cm} / \mathrm{s}^{2}\end{array}\right.$

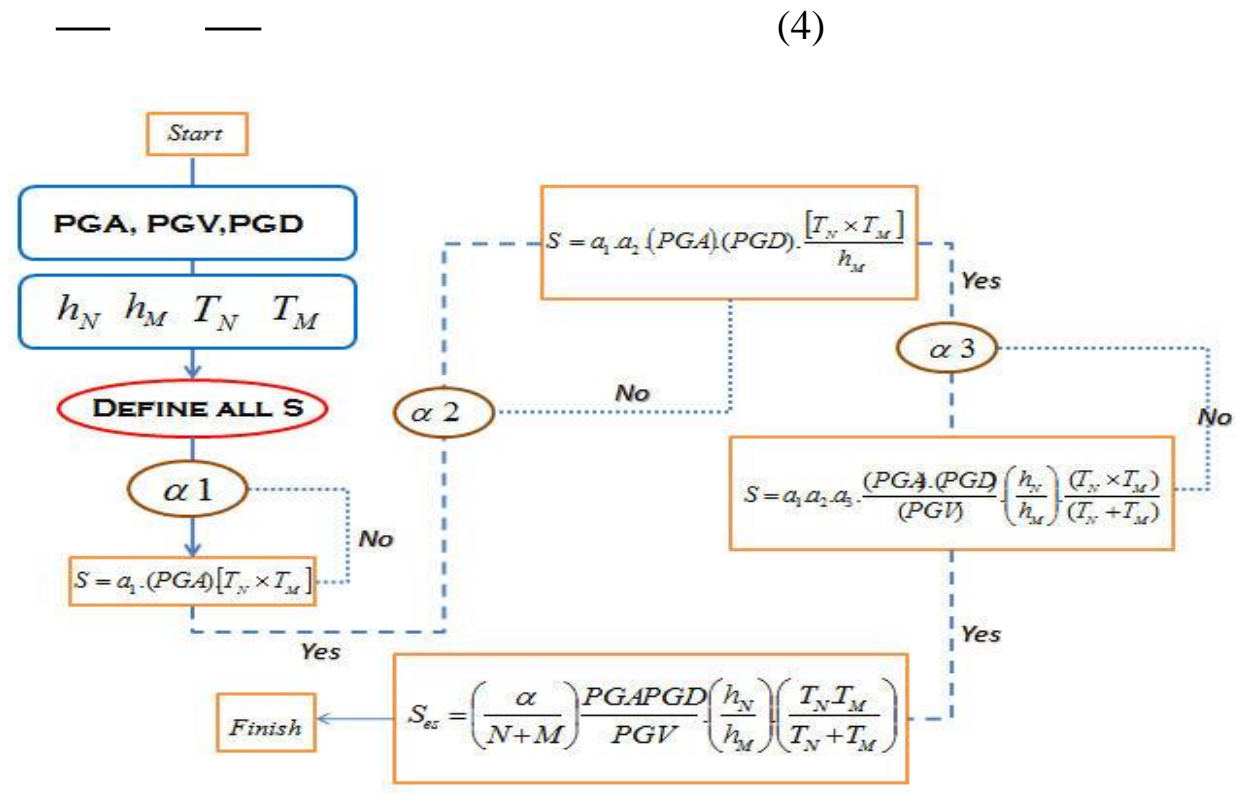

Figure 4 The flowchart of algorithm methodology of using neural network

\section{RESULTS}

In order to investigate the accuracy of suggested formula, two different ways are considered.

\section{- Model with different earthquake records}

An assumed irregular model with a two and a four story model is dynamically considered (24). The height of each story is 3 meters, which make a total height of 6 and 12 meters and the period of models are $1.24 \mathrm{~s}$ and $2.018 \mathrm{~s}$ for two and four story model, respectively. Columns are $30 * 30 \mathrm{~cm}$ at the first and second story and are $25 * 25 \mathrm{~cm}$ at the third and fourth story. The damnation of beams is $25 * 30 \mathrm{~cm}$ for all beams. The soil of the land is also assumed to be same for two models (Figure 5).

The mass of four story is assumed to be 40000, 32000, 24000 and $16000 \mathrm{~kg}$ and the stiffness 
of each story is also $2^{*} 10^{6}, 1.6^{*} 10^{6}, 1.2^{*} 10^{6}$ and $0.8^{*} 10^{6} \mathrm{~kg} / \mathrm{m} 2$ for first to fourth story. The mass of two story is 24000 and $16000 \mathrm{~kg}$ and the stiffness of each story is $1.2^{*} 10^{6}$ and $0.8^{*} 10^{6}$ $\mathrm{kg} / \mathrm{m} 2$ for first and second story. In order to explain the value of masses, as the plan of original model is considered to be square and the program needs to define an irregularity in height, as lumped masses is located in one direction, increasing the value of masses is caused to provide irregularity based on which is defined. In order to investigate the accuracy of the results, an irregular 3- story model is performed and analyses by SAP2000 and the results of the lateral displacement of top story model is compared with the results of the used program. It seems that the results of the program are logically confirmed. According to the mentioned details and in order to investigate the accuracy of formula, among seven earthquake records, three earthquake records with different peak ground acceleration from 6.5 to 7.2 are randomly selected with different peak ground acceleration which are Kobe, Loma Prieta and Imperial Valley. Using suggested formula, properties of earthquakes and characteristics of models, separation distance between structures are calculated to be $25.84 \mathrm{~cm}, 25.95 \mathrm{~cm}$ and $46.61 \mathrm{~cm}$ for mentioned earthquake records. Providing gap size, determined by suggested formula, is caused to safety space between two models which obviously shown in Figures 6. It is mentioned that 2-4 model has been randomly selected to investigate and evaluate the proposed formula and the results of analyses, which can use for all situations and models.

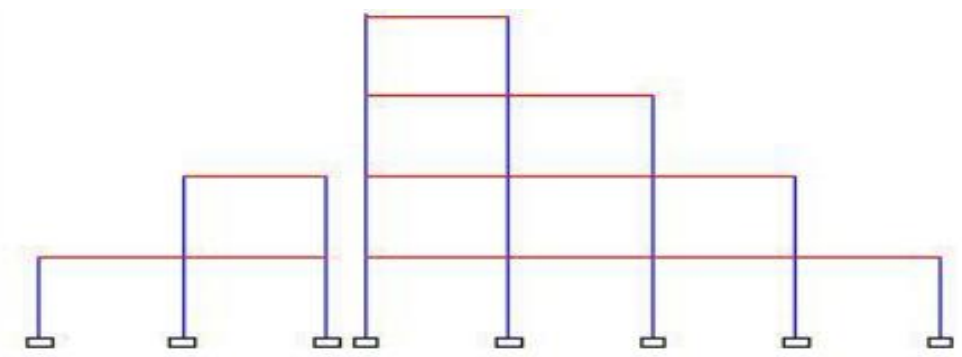

Figure 5 Elevation of two and four story model (2-4) 

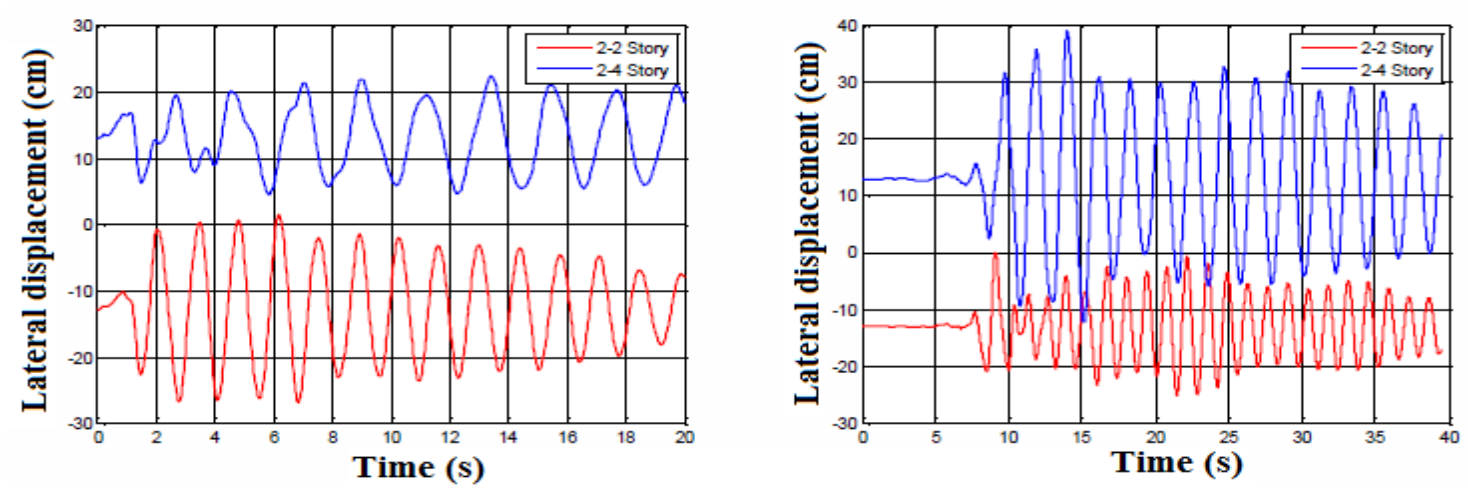

b

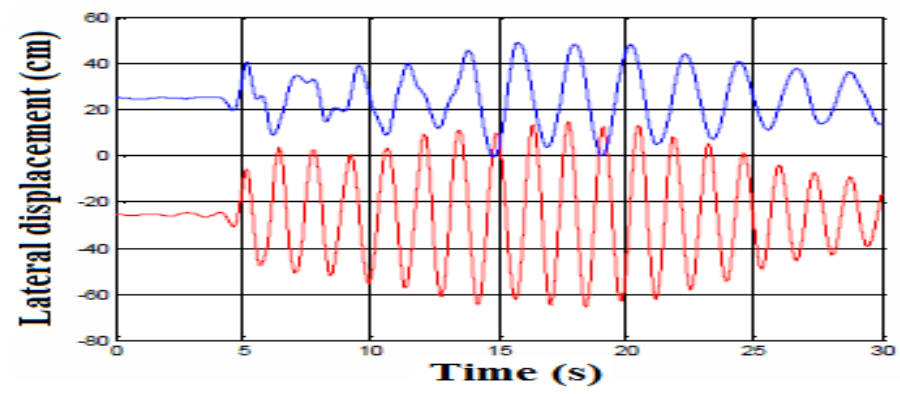

C

Figure 6 The results of lateral displacement of second story of two and four story model with (a) Kobe (b) Loma Prieta and (c) Imperial Valley

It can be seen in Figure 6 that the proposed formula has shown acceptable results using different earthquake records. The models with three different earthquake records have been optimally separated to avoid collision and provided safety situation when earthquake records are activated. In this part, Kobe earthquake record has the minimum lateral displacement compared with other earthquake records. Finally, the results of analyses has presented that the accuracy of the proposed formula is confirmed and can be used for various situation and different earthquake records.

\section{- Gap size with different equations}

In order to compare the value of separation distance between two irregular buildings with other suggestions, used model in previous part is perfectly assumed and Tabas earthquake record is selected for lateral loading. Maximum lateral displacements of models are $43.36 \mathrm{~cm}$ and $51.85 \mathrm{~cm}$ for two and four story model, respectively. Thus, separation distance is demonstrated as [see equations in Kasai et al. (1996) and Naderpour et al. (2017):

Table 2 Separation distance using three different equations.

\begin{tabular}{|c|c|c|c|}
\hline Earthquake & Kasai et al. (1996) & Naderpour et al. (2017) & Proposed formula \\
\hline Separation distance & 62.23 & 59.07 & 75.75 \\
\hline
\end{tabular}


Figure 7 demonstrates lateral displacement of 2-4 models, respecting to separation distance by using table 2. As it is seen, separation distances by Kasai et al. (1996) and Naderpour et al. (2017) have shown some collisions between adjacent buildings which have not accorded in the model, calculated by proposed formula.

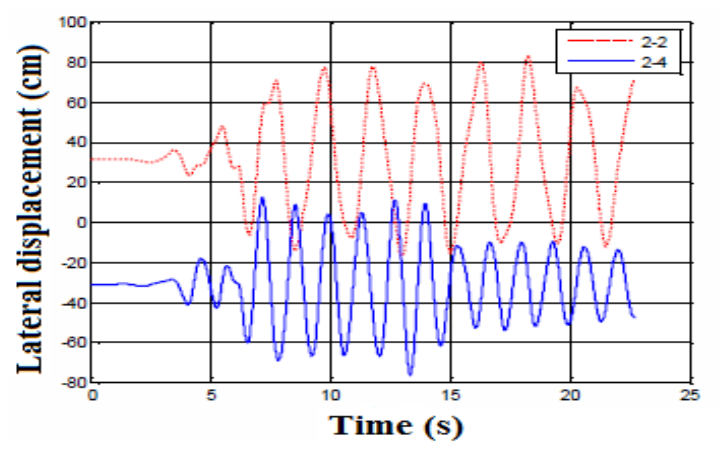

a

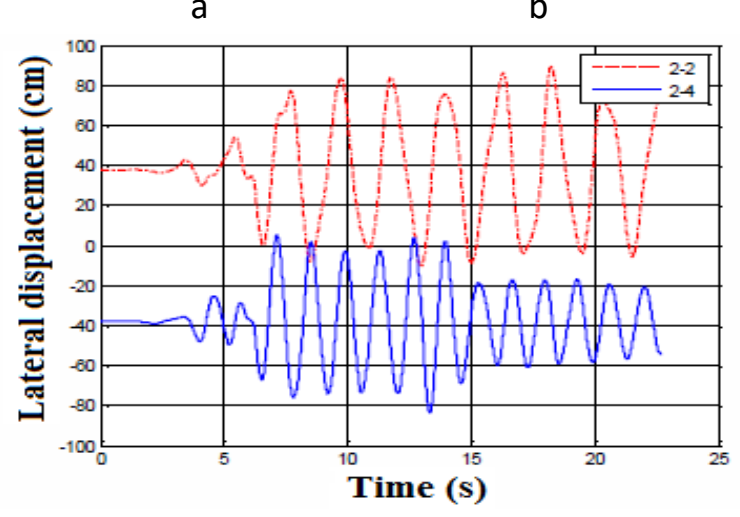

C

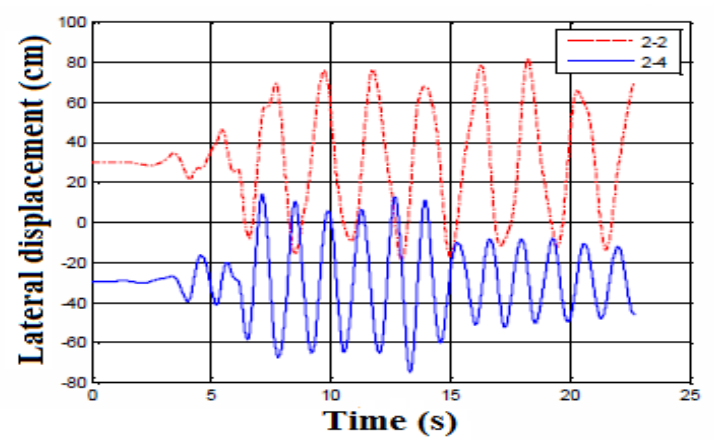

b 证

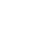


So, investigation of the model with different earthquake records and also different formulas has shown that the proposed formula describes optimum required separation distance between two adjacent irregular models.

\section{CONCLUSIONS}

The aim of the study is to focus on separation distance between two irregular adjacent buildings during seismic excitations to prevent collision due to large lateral displacement. The majority of earthquake codes and researches have suggested some equations based on maximum lateral displacement of each model or some characteristics of building such as height of model, period and damping ratio. Although mentioned parameters are considered as main factors to calculate critical distance, but it seems that the properties of earthquake has also significant effects in the behavior of building in field of lateral displacements to determine separation gap between structures. The number of story is also considered as an effectible parameter to demonstrate safety gap size, avoided to collision. For the purpose, five irregular buildings are modeled and seven different earthquake records are defined to analyze and investigate optimum separation distance. Two structures are considered to be located close one to another, taking into account all possible combinations from the point of view of different number of stories and analyzed with mentioned earthquake records to predict the least and optimum separation gap which covers sufficient distance. All calculated distances are collected and listed to make special trend based on PGA of earthquakes. Finally, a new equation is suggested using all effective parameters such as period and height of buildings, the number of stories, peak ground displacement, velocity and acceleration to calculate separation distance. In order to investigate the accuracy of proposed formula, firstly, a 2-4 story model is considered and separated with sufficient distance, calculated by proposed formula and evaluated by three different earthquake records. Secondly, value of critical distance, 
determined by three various formulas are assumed and analyzed by Tabas earthquake. Consequently, the results of analyses show that proposed formula is able to provide sufficient separation distance between two irregular adjacent buildings. Consequently, different equations determine various values for critical distance to provide safety space between buildings or some codes around the world suggest special value based on height of buildings while the proposed formula in this study has comprehensively used all effective parameters such as properties of buildings and also earthquake such as building vibration periods of both builings, the height of them, peak ground accerelation, vibration and displacement to calculate optimum gap size between two adjacent buildings.

\section{REFERENCES}

Aguilar, J., Jurez, H., Ortega, R. \& Iglesias, J. 1989. The Mexico earthquake of September 19, 1985 - statistics of damage and of retrofitting techniques in reinforced concrete buildings affected by the 1985 earthquake. Earthquake Spectra. 5 (1): 145-151.

ASCE, 2005. Minimum design load for buildings, American Society of Civil Engineering, USA.

Anajafi H. \& Medina R.A. 2019. Lessons learned from evaluating the responses of instrumented buildings in the United States: the effects of supporting building characteristics on floor response spectra. Earthquake Spectra. 35 (1): 159-191.

Anajafi H., Poursadr K., Roohi, M. \& Santini Bell, E. 2020a. Effectiveness of seismic isolation for long-period structures subject to far-field and near-field excitations. Frontiers in Built Environment. $6(24)$.

Anajafi, H., Medina R.A. \& Santini Bell E. 2020b. Effects of the improper modeling of viscous damping on the first mode and higher mode dominated responses of base isolated buildings. Earthquake Engineering and Structural Dynamics. 49 (1): 51-73. 
Bi, K., Hao, H. \& Sun, Z. 2017. 3D FEM analysis of earthquake induced pounding responses between asymmetric buildings. Earthquakes and Structures. 13 (4): 377-386.

Charney F.A. 2008. Unintended consequences of modeling damping in structures. Journal of Structural Engineering. 134 (4): 581-592.

Der Kiureghian, A. 1981. A response spectrum method for random vibration analysis of MDF systems. Earthquake Engineering and Structural Dynamics. 9 (5): 419-435.

Filiatrault, A. \& Cervantes, M. 1995. Separation between buildings to avoid pounding during earthquakes. Canadian Journal of Civil Engineering. 22 (1): 164-179.

Garcia, D.L. 2004. Separation between adjacent non-linear structures for prevention of seismic pounding. Proceedings of 13th World Conference on Earthquake Engineering. Vancouver, Canada.

Ghomi Gharaei A., Anajafi H. \& Ghorbani Tanha A.K. 2013. Comparison of footing design codes criteria and foundation effects on structural seismic behavior. Proceedings of the 4th International Conference on Concrete and Development. Tehran, Iran.

Hao, H. \& Shen, J. 2001. Estimation of relative displacement of two adjacent asymmetric structures. Earthquake Engineering and Structural Dynamics. 30 (1): 81-96.

Jankowski, R. 2009. Non-linear FEM analysis of earthquake induced pounding between the main building and the stair way tower of the Olive View Hospital. Engineering Structures. 31: 18511864.

Jeng, V. \& Tzeng, W.L. 2000, Assessment of seismic pounding hazard for Taipei City. Engineering Structures. 22 (5): 459-471.

Kamgar, R., Naderpour, H., Komeleh, H.E., Jakubczyk Gałczyńska, A. \& Jankowski, R. 2020. A proposed soft computing model for ultimate strength estimation of FRP-confined concrete cylinders. Applied Sciences. 10 (5).

Kasai, K., Jagiasi, A.R. \& Jeng, V. 1996. Inelastic vibration phase theory for seismic pounding mitigation. Journal of Structural Engineering. 122 (10): 1136-1146. 
Kasai, K. \& Maison, B.F. 1997. Building pounding damage during the 1989 Loma Prieta earthquake. Engineering Structures. 19 (3): 195- 207.

Khatami, S.M., Naderpour, H., Barros, R.C. \& Jankowski R. 2019. Verification of equation of motion for periods of adjacent buildings used to assess minimum separation gap preventing structural pounding during earthquakes. Advance in Civil Engineering.

Kheyroddin, A., Kioumarsi, M., Kioumarsi, B. \& Faraei, A. 2018. Effect of lateral structural systems of adjacent buildings on pounding force. Earthquakes and Structures. 14 (3): 229-239.

Léger P. \& Dussault, S. 1992. Seismic energy dissipation in MDOF structures. Journal of Structural Engineering. 118 (5): 1251-1269.

Lin, J.H. \& Weng, C. 2002. A study on seismic pounding probability of buildings in Taipei metropolitan area. Journal of the Chinese Institute of Engineers. 25 (2): 123-135.

Loghmani, A., Mortezaei, A. \& Hemmati, A. 2020. A new equation based on PGA to provide sufficient separation distance between two irregular buildings in plan. Earthquake and Structures. 18 (5): 543-553.

Naderpour, H., Barros, R.C. \& Khatami, S.M. 2017. Prediction of critical distance between two MDOF systems subjected to seismic excitation in terms of artificial neural networks. Periodica Polytechnica Civil Engineering. 61 (3): 516-529.

Pantelides, C.P. \& Ma, X. 1998. Linear and nonlinear pounding of structural systems. Computers and Structures. 66 (1): 1136-1146.

Penzien, J. 1997. Evaluation of building separation gap required to prevent pounding during strong earthquakes. Earthquake Engineering and Structural Dynamics. 26 (8): 849-858.

Valles, R.E. \& Reinhorn, A.M. 1997. Evaluation, prevention and mitigation of pounding effects in building structures. Technical Report No. NCEER-97-0001. National Center for Earthquake Engineering Research. University of Buffalo. Buffalo. USA.

Varnotte, V. 2008. Mitigation of pounding between adjacent buildings in earthquake situation. Ph.D. Dissertation. University of Liege, Liege, Belgium.S 